OPEN ACCESS

Edited by:

Guobing Chen,

Jinan University, China

Reviewed by:

Julia Eckl-Dorna,

Medical University of Vienna, Austria

Kishore Alugupalli,

Thomas Jefferson University,

United States

${ }^{*}$ Correspondence:

Rita Carsetti

rita.carsetti@opbg.net

Specialty section: This article was submitted to

B Cell Biology,

a section of the journal

Frontiers in Immunology

Received: 03 April 2021 Accepted: 09 July 2021

Published: 23 July 2021

Citation:

Ciocca M, Zaffina $S$,

Fernandez Salinas A, Bocci C,

Palomba P, Conti MG, Terreri S,

Frisullo G, Giorda E, Scarsella M, Brugaletta R, Vinci MR, Magnavita N, Carsetti $R$ and Piano Mortari E (2021)

Evolution of Human Memory B Cells

From Childhood to Old Age.

Front. Immunol. 12:690534.

doi: 10.3389/fimmu.2021.690534

\section{Evolution of Human Memory B Cells From Childhood to Old Age}

\author{
Michela Ciocca ${ }^{1}$, Salvatore Zaffina ${ }^{2,3}$, Ane Fernandez Salinas ${ }^{1,4}$, Chiara Bocci ${ }^{1}$, \\ Patrizia Palomba ${ }^{5}$, Maria Giulia Conti ${ }^{4,6}$, Sara Terreri ${ }^{1}$, Giuseppe Frisullo ${ }^{1}$, Ezio Giorda ${ }^{7}$, \\ Marco Scarsella ${ }^{7}$, Rita Brugaletta ${ }^{2,3}$, Maria Rosaria Vinci ${ }^{2,3}$, Nicola Magnavita ${ }^{8,9}$, \\ Rita Carsetti ${ }^{1,5^{*}}$ and Eva Piano Mortari ${ }^{1}$
}

\begin{abstract}
1 Diagnostic Immunology Research Unit, Multimodal Medicine Research Area, Bambino Gesù Children's Hospital, IRCCS, Rome, Italy, ${ }^{2}$ Occupational Medicine/Health Technology Assessment and Safety Research Unit, Clinical-Technological Innovations Research Area, Bambino Gesù Children's Hospital, IRCCS, Rome, Italy, ${ }^{3}$ Health Directorate, Occupational Medicine, Bambino Gesù Children's Hospital, IRCCS, Rome, Italy, ${ }^{4}$ Department of Molecular Medicine, Sapienza University of Rome, Rome, Italy, ${ }^{5}$ Diagnostic Immunology Clinical Unit, Department of Diagnostic and Laboratory Medicine, Bambino Gesù Children's Hospital, IRCCS, Rome, Italy, ${ }^{6}$ Department of Maternal and Child Health, Policlinico Umberto I, Sapienza University of Rome, Rome, Italy, ${ }^{7}$ Core Facilities, Bambino Gesù Children's Hospital, IRCCS, Rome, Italy, ${ }^{8}$ Post-Graduate School of Occupational Health, Section of Occupational Medicine and Labor Law, Università Cattolica del Sacro Cuore, Rome, Italy, ${ }^{9}$ Department of Woman, Child \& Public Health, Fondazione Policlinico Universitario A. Gemelli IRCCS, Rome, Italy
\end{abstract}

High quality medical assistance and preventive strategies, including pursuing a healthy lifestyle, result in a progressively growing percentage of older people. The population and workforce is aging in all countries of the world. It is widely recognized that older individuals show an increased susceptibility to infections and a reduced response to vaccination suggesting that the aged immune system is less able to react and consequently protect the organism. The SARS-CoV-2 pandemic is dramatically showing us that the organism reacts to novel pathogens in an age-dependent manner. The decline of the immune system observed in aging remains unclear. We aimed to understand the role of $B$ cells. We analyzed peripheral blood from children (4-18 years); young people (23-60 years) and elderly people (65-91 years) by flow cytometry. We also measured antibody secretion by ELISA following a T-independent stimulation. Here we show that the elderly have a significant reduction of $\mathrm{CD} 27^{\text {dull }}$ memory $\mathrm{B}$ cells, a population that bridges innate and adaptive immune functions. In older people, memory B cells are mostly high specialized antigen-selected CD27 bright. Moreover, after in vitro stimulation with $\mathrm{CpG}, \mathrm{B}$ cells from older individuals produced significantly fewer IgM and IgA antibodies compared to younger individuals. Aging is a complex process characterized by a functional decline in multiple physiological systems. The immune system of older people is well equipped to react to often encountered antigens but has a low ability to respond to new pathogens.

Keywords: B cell, CD27, T cell-independent B-cell activation, aging, memory B cell (MBC) 


\section{INTRODUCTION}

The progressive deterioration of the immune system in aged individuals is termed "immunosenescence" (1). This process entails an impairment of the immune response with a consequent increased susceptibility to emerging pathogens and a reduced responsiveness to vaccination (2-4). As a consequence, older individuals showed an increased morbidity (4) and mortality (5).

The aging of workers is one of the most important issues for occupational health and safety in Europe. The EU's demographic old-age dependency ratio (i.e., the ratio between people aged 65 years and over and those aged 20-64) is projected to increase significantly in the coming decades. From about 29\% in 2010, it is projected to rise to $59 \%$ in 2070 (6). Labor force participation is projected to increase, in particular among older workers, on account of implemented pension reform. Keeping workers active and productive through health promotion intervention is a prime objective of European labor policy $(7,8)$. This task requires adapting work environments to the changing characteristics of the workforce, taking into account the high prevalence of chronic diseases in older workers and their greater sensitivity to infections (9). The SARS-CoV-2 pandemic is dramatically showing us that the organism reacts to novel pathogens in an age-dependent manner. Disease severity and mortality rate are highest in the elderly, especially when coexisting morbidities further weaken the organism $(10,11)$ rendering the immune response against the virus less effective (12-14).

With aging, the organism experiences a progressive impairment of both the innate and adaptive arm of the immune system (1), where thymic involution and the decreased output of $\mathrm{T}$ cells are probably the most recognized signs (15). Many other immune cell functions are affected by aging, such as reduced antigen-presenting and cytokine secretion ability of macrophages and follicular dendritic cells $(16,17)$ and diminished neutrophils phagocytic activity (18). In addition, T cell repertoire and $\mathrm{T}$ cell responsiveness are reduced $(19,20)$.

On the other hand, the role of $\mathrm{B}$ cells in immune aging remains unclear. Recent findings illustrate major shifts in B cell subsets in the elderly, suggesting that age-related changes in B cells may contribute to immunosenescence (21).

Immunological memory is the ability of our immune system to remember previously encountered pathogens; it is acquired by experience and it changes throughout life affecting our susceptibility to infections. Neonates and children under 5 years are more susceptible to infections compared to adults, because they are continuously exposed to pathogens that they have never encountered before (22). Infections are rare in adults thanks to their large repertoire of specific memory $\mathrm{T}$ and $\mathrm{B}$ cells generated by previous antigenic experiences. In the elderly, susceptibility to infections increases again (23).

Respiratory tract infections are a major cause of disease during old age (24) when the response to vaccination is decreased (25). Encapsulated bacteria (mostly Streptococcus pneumoniae) are the main cause of respiratory tract infections and a leading cause of mortality in people $>65$ years old (26).
As for respiratory infections, also gastrointestinal infectious diseases in the elderly are common (27) suggesting that mucosal immune responses could be compromised (24).

We focused our attention on B cells that change with age in number and type (21). As a result of infection or vaccination, $B$ cells become memory B cells (MBCs) and plasmablasts (PBs) able to produce high affinity antigen-specific antibodies. MBCs can be identified by the expression of the CD27 marker (28). The intensity of expression of CD27 defines two populations, $\mathrm{CD} 27^{\text {dull }}$ and $\mathrm{CD} 27^{\text {bright }} \mathrm{MBCs}$.

CD27 ${ }^{\text {dull }}$ MBCs can be generated without $\mathrm{T}$ cells and germinal center (GC) and are mostly of the IgM isotype. Instead, $\mathrm{CD} 27^{\text {bright }} \mathrm{MBCs}$ are generated exclusively in the GC by a $\mathrm{T}$ cell-dependent mechanism and under a strong selective pressure by an antigen (Ag). For this reason, the frequency of somatic mutations (SMs) is low in CD27 $7^{\text {dull }}$ MBCs and significantly higher in $\mathrm{CD} 27^{\text {bright }} \mathrm{MBCs}$ (28). We have shown that $\mathrm{CD} 27^{\text {dull }}$ MBCs are the precursors of the CD2 $7^{\text {bright }}$ MBCs and that the human $\mathrm{MBC}$ pool is organized in large clones with a root of $\mathrm{CD} 27^{\text {dull }} \mathrm{MBC}$ s of the IgM isotype, gradually acquiring more SM and finally generating highly mutated MBCs of IgM or switched isotypes. $\mathrm{CD} 27^{\text {bright }} \mathrm{MBC}$ are closer to the plasma cell stage than $\mathrm{CD} 27^{\text {dull }}$ MBCs. In a previous study, we sorted $\mathrm{CD} 27^{\text {dull }}$ and $\mathrm{CD} 27^{\text {bright }} \mathrm{MBCs}$ and demonstrated that upon stimulation $\mathrm{CD} 27^{\text {bright }} \mathrm{MBCs}$ undergo rapid and extensive proliferation and differentiate in large number of plasmablasts more effectively than CD27 ${ }^{\text {dull }}$ MBCs (28).

The reduction of $\mathrm{CD} 27^{\text {dull }}$ IgM MBCs correlates with an impaired immune response to encapsulated bacteria in infants, splenectomized and asplenic individuals, and patients with primary or secondary immune deficiency (29). With age, IgM MBCs decrease (30). Moreover, aging has an impact on the splenic marginal zone (MZ) that is known to be the site where CD27 ${ }^{\text {dull }}$ IgM MBCs $(31,32)$ are located.

Here we show that, compared to children, elderly individuals have more $\mathrm{CD} 27^{\text {bright }} \mathrm{MBCs}$, suggesting that their immune system may be equipped to react against well-known antigens but has a reduced ability to respond to new pathogens.

Moreover, after in vitro stimulation with $\mathrm{CpG}, \mathrm{B}$ cells from elderly individuals produced significantly fewer IgM and IgA antibodies compared to younger individuals.

\section{MATERIALS AND METHODS}

\section{Ethical Approval}

Ethical approval was obtained from the Ethics Committee at the Bambino Gesù Children Hospital. According to the guidelines on Italian observational studies as established by the Italian legislation about the obligatory occupational surveillance and privacy management, health care workers' confidentiality was safeguarded and informed consent was obtained from all the participants. The study was performed in accordance with the Good Clinical Practice guidelines, the International Conference on Harmonization guidelines, and the most recent version of the Declaration of Helsinki. 


\section{Human Samples}

We analyzed peripheral blood from children (4-18 years); young people (23-60 years) and elderly people (65-91 years). Young and elderly individuals were health care workers from our hospital, the majority of whom were active, while others were already retired. Older individuals were screened by interview to ensure they did not have autoimmune diseases, tumors, or recent infections.

At the time of blood sampling, none of the subjects had an acute infection or were taking any medication known to alter immune function (such as steroids or statins).

\section{Cell Isolation}

Heparinized peripheral blood was collected and then centrifuged through a Histopaque gradient (Ficoll Paque ${ }^{\mathrm{TM}}$ Plus 206, Amersham Pharmacia Biotech) for $25 \mathrm{~min}$ at $2400 \mathrm{rpm}$. PBMCs were collected from the interface. Next, PBMCs were spun down and washed twice with RPMI 1640 medium (Euroclone). Then PBMCs were frozen and stored in liquid nitrogen until use. The freezing medium contained 90\% Fetal Bovine Serum (FBS) and 10\% DMSO.

\section{Stimulation and Reagents}

PBMCs were loaded with Carboxyfluorescein succinimidyl ester (CFSE, Life Technologies). Briefly, $1 \times 10^{6}$ cells $/ \mathrm{ml}$ were resuspended in PBS (Euroclone) with 1\% FBS (Gibco BRL) and loaded with $1 \mu \mathrm{M}$ CFSE for $20 \mathrm{~min}$ at $37^{\circ} \mathrm{C}$. After washing, cells (at a concentration of $5 \times 10^{6}$ cells $/ \mathrm{ml}$ ) were stimulated with $0.35 \mu \mathrm{M}$ of TLR9 agonist CpG-B ODN2006 (Hycult Biotech) in complete medium for 5 days at $37^{\circ} \mathrm{C}$. Complete medium was prepared as follows: RPMI-1640 (Euroclone), 10\% heat inactivated fetal bovine serum (FBS, Hyclone Laboratories), 1\% L-Glutammine (Gibco BRL); 1\% Penicillin/Streptomicin 100X (Euroclone), 1\% sodium pyruvate (Gibco BRL).

\section{ELISA Immunoassay}

Following CpG stimulation (5 days), we performed an ELISA to detect secreted immunoglobulin in the supernatant of the stimulated cells. Briefly, 96-well plates (Costar3590 EIA/RIA plate) were coated overnight with purified goat anti-human IgA+IgG+IgM ( $\mathrm{H}+\mathrm{L}$ chain; Jackson ImmunoResearch Laboratories). After washing with PBS containing $0.05 \%$ Tween and blocking with PBS containing $1 \%$ gelatin $(1 \mathrm{~h}$, room temperature), plates were incubated for $1 \mathrm{~h}$ at $37^{\circ} \mathrm{C}$ with the supernatants of cultured cells. After removing the supernatants and washing, plates were incubated for $1 \mathrm{~h}$ with peroxidase-conjugated fragment goat anti-human IgA or IgG or IgM antibodies (Jackson ImmunoResearch Laboratories). The assay was developed with O-phenylendiamine tablets (SigmaAldrich) as a chromogenic substrate. Absorbance at $450 \mathrm{~nm}$ was measured, and immunoglobulin concentrations were calculated by interpolation with the standard curve.

\section{Flow Cytometry and Antibodies}

A total of $50 \mathrm{ul}$ of total peripheral blood was used for enumeration of CD45+ cells using the DuraClone IM Count (Beckman Counter) following the manufacturer's instructions.
PBMCs were stained with the appropriate combination of fluorochrome-conjugated antibodies to identify B cell subsets according to standard techniques. Used antibodies were: CD19, CD21, CD24, CD27, CD38, IgG, IgA, and IgM (Table S1). Acquisition was performed on a BD LSRFortessa X-20 (BD Biosciences) and data were analyzed with FlowJo ver.8 (Treestar). Proliferation was measured through the analysis of CFSE dilution. The FlowJo's Proliferation tool looks for a pattern typically expressed by cells loaded with fluorescent dye (CFSE in our case) and is allowed to divide. The FlowJo's Proliferation platform calculates the proliferation index (PI) that corresponds to the mean number of divisions of all cells that have responded (Proliferation Index: Total Number of Divisions/Cells that went into division). We also calculated the replication index (RI) that indicates the fold-expansion of only the responding cells (Replication Index: Total Number of divided cells/The number of cells that went into division). These two indices reflect the intrinsic ability of the different cell types to respond to signals (33).

\section{Statistical Analysis}

Values were compared by the non-parametric Kruskal-Wallis test and, if significant, pairwise comparisons were evaluated by the Mann-Whitney U test nonparametric test. A level of $\mathrm{p}<0.05$ was considered statistically significant. ${ }^{\star} \mathrm{p}<0.05 ;{ }^{\star *} \mathrm{p}<0.01$, and ${ }^{* * *} \mathrm{p}<0.001$

\section{RESULTS}

\section{Immunophenotype of B Cells}

We determined the frequencies and absolute numbers of $B$ cell populations of children ( $\mathrm{n}=37$; $4-18$ years) and adults of different ages $(20-40$ years, $n=18)$; $(65 \geq$ years $<70, n=21)$ and over 70 years $(n=9)$. We excluded infants from our analysis because their memory B cell pool is mainly represented by CD27 ${ }^{\text {dull }}$ MBCs. Peripheral blood mononuclear cells (PBMCs) were stained with antibodies to CD19, CD21, CD24, CD27, CD38, CD45, and IgM. The gating strategy used to identify B cell population is shown in Figure S1. Absolute numbers were calculated by staining blood samples with the DuraClone IM Count (Beckman Counter).

Children have the highest frequency of $\mathrm{B}$ cells in the peripheral blood compared to adults of all ages, (CD19+) (Figure 1A) (19). B cells are increased in absolute numbers in young adults probably because of an overall increase in the CD45+ lymphocytes count (Figure 1A). The percentages of naïve B cells (CD19+, CD24+, CD27-) appears to be similar in the four groups but absolute numbers indicate a significant decrease in the elderly group probably because of the reduction of total B cells (Figure 1B). Transitional B cells (CD19+, CD24+, CD38++), the most immature B cell subtype in the blood, are highest in children and significantly decrease with age, both in percentage and absolute numbers (Figure 1C).

The percentage of MBCs (CD19+, CD24+, CD27+) is significantly increased in the young and older adult groups compared to children (Figure 1D). As for naive B cells, the 



FIGURE 1 | Percentage and absolute numbers of (A) B cells; (B) naïve B cells; (C) transitional B cells; (D) memory B cells (MBCs); (E) plasmablasts, and (F) atypical MBCs (ATM) at the indicated ages (children $n=37$; young $n=18$; $65 \geq$ years $<70 n=21$; over 70 years $n=9$ ). Midlines indicate the median values. Statistical significances were determined using unpaired, two-tailed Mann-Whitney U-tests. ${ }^{\star} p \leq 0.05 ;{ }^{\star \star} p<0.01$; ${ }^{\star \star \star} p<0.001$.

total B cell number has a strong impact on $\mathrm{MBC}$ absolute numbers and the young group has the highest value compared to the others (Figure 1D). In contrast, the percentage of plasmablasts (CD19+, CD27+, CD38++) significantly increased in the over 70 group (Figure 1E). Atypical memory B cells (ATM) have been described in aged mice and are distinct from other B cell subsets $(34,35)$. In humans, they increase in the course of autoimmune diseases (35-37) and infections (38-40), and are thought to reflect a failure or impairment of the germinal center reaction (41). Both percentage and absolute number of ATM (CD19++, CD24-, CD38-, CD21-) were increased in the elderly group (Figure 1F) (42).

\section{CD27 ${ }^{\text {dull }}$ and CD27 $7^{\text {bright }}$ Memory B Cells}

CD27 is the marker that allows the identification of MBCs. Our group have recently demonstrated that MBCs comprise two cell populations, $\mathrm{CD} 27^{\text {dull }}$ and $\mathrm{CD} 27^{\text {bright }} \mathrm{MBCs}$, which are related but have distinct molecular signatures and functions (28). Thus, we examined CD27 intensity in our different age groups. The gating strategy to identify the two MBCs population of each group (gated in CD19+ B cells) is shown in Figure 2A. We observed a significant reduction in percentage and absolute number of $\mathrm{CD} 27^{\text {dull }} \mathrm{MBCs}$ in the two groups of older people compared to young adults (Figure 2B). Instead, the percentage of $\mathrm{CD} 27^{\text {bright }} \mathrm{MBCs}$ is significantly lower in the children group compared to the other groups (Figure 2C). Interestingly, the absolute number of CD2 $7^{\text {bright }} \mathrm{MBCs}$ is significantly increased in the young group, probably because of the higher number of total B cells compared to the other groups (Figure 2C).

For our health, it is important to have both $\mathrm{CD} 27^{\text {dull }}$ and $\mathrm{CD} 27^{\text {bright }} \mathrm{MBCs}$ since they play different and noninterchangeable roles (28). In order to evaluate the relative size of the two pools, we calculated the ratio between the absolute numbers of $\mathrm{CD} 27^{\text {dull }}$ and $\mathrm{CD} 27^{\text {bright }} \mathrm{MBC}$ s at different ages. We found that in the older groups the ratio is significantly lower compared to the two youngest groups (Figure 2D), confirming a dramatic reduction of $\mathrm{CD} 27^{\text {dull }}$ compared to $\mathrm{CD} 27^{\text {bright }} \mathrm{MBCs}$.

\section{CpG Stimulation}

The imbalance of B cell frequency is undoubtedly important, nevertheless it is essential to evaluate the ability of B cells to respond to stimuli. Upon T-independent (TI) stimulation with CpG, a ligand of the toll-like receptor 9 (TLR9), B cells proliferate, differentiate into plasmablasts (identified as $\mathrm{CD} 19^{\text {low }}, \mathrm{CD} 27++$, CD38++), and secrete immunoglobulins (43).

In order to prove their function, PBMCs of children, young and elderly people were cultured for 5 days with $\mathrm{CpG}$ and then analyzed by flow cytometry. By ELISA, we measured the amount of IgM, IgG, and IgA in the culture supernatants. Due to the low cell numbers, it was not possible to perform the stimulation on 
A



young



$65 \geq$ years $<70$



over 70 years

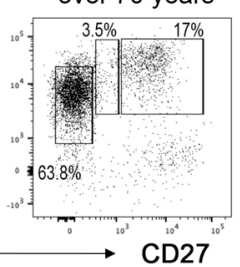

B
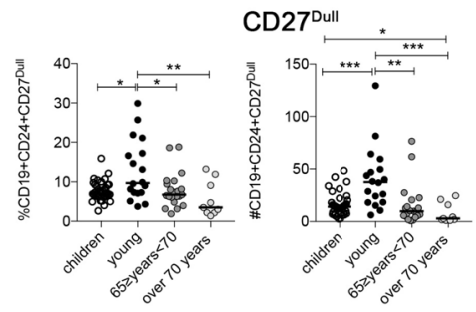

D

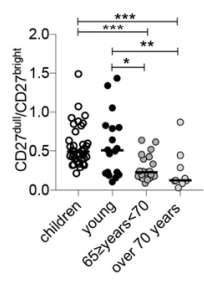

C



FIGURE 2 | (A) Identification of naive, CD27 $7^{\text {dull }}$, and CD27 $7^{\text {bright }}$ MBCs at the indicated ages. (B, C) Percentage and absolute numbers of (B) CD27 ${ }^{\text {dull }}$ and (C) CD27 ${ }^{\text {bright }}$ MBCs. (D) Ratio of CD27 $7^{\text {dull }}$ and CD27 ${ }^{\text {bright }} M B C s$ at the indicated ages (children $n=37$; young $n=18$; $65 \geq$ years $<70 n=21$; over 70 years $n=9$ ). Midlines indicate the median values. Statistical significances were determined using unpaired, two-tailed Mann-Whitney $U$-tests. ${ }^{*} p \leq 0.05 ;{ }^{* *} p<0.01 ;{ }^{* \star *} p<0.001$.

all the samples within each group (19 children, 4 young subjects, and 2 subjects of the $65 \geq$ years $<70$ were excluded).

FACS analysis of four representative samples is reported in Figure 3, and the histogram depicts the $\mathrm{B}$ cell proliferation evaluated by tracking the dilution of the fluorescent dye CFSE.

The percentage of in vitro-produced plasmablasts was similar between the four groups (Figure 4A), suggesting that the ability of MBCs to differentiate in plasmablasts following a TI stimulation is not affected in elderly people. We evaluated also the proliferation and replication index values. The proliferation index is the average number of divisions that all responding cells have undergone since the initiation of the culture and reflects the proliferative capacity of the cells in response to CpG. This index is calculated by dividing the total number of cells that proliferated by the number of cells that went into division.

The replication index determines the fold-expansion of only responding cells and reflects the expansion capacity of the replicating cells rather than the entire culture.

The two indexes were significantly higher in the two oldest groups compared with the children and with the young group (Figure 4B).

Although B cells from older groups proliferate and replicate extensively and differentiate into $\mathrm{PB}$, they secrete fewer immunoglobulins. In particular, IgM and IgA levels were significantly reduced in the two groups of older people and the level of IgG was reduced in the over 70 group (Figure 4C).

\section{DISCUSSION}

High quality medical assistance and preventive strategies, including pursuing a healthy lifestyle, result in a progressively growing percentage of older people in life and the working environment. It is widely recognized that older individuals show an increased susceptibility to infections and a reduced response to vaccination suggesting that the immune system is less able to react and consequently protect the organism. This represents a burden on health care costs and furthermore raises the question of which interventions may guarantee a good quality of life and reduce the risk of avoidable age-related diseases. The current COVID-19 pandemic emergency has strongly demonstrated that older individuals are more fragile when challenged by an unknown pathogen, fostering the need to understand which mechanisms differentiate the aged immune system from that of a young individual.

It has been recently published (44) that the different responses between young and older individuals are due to the different types of cells that prevail in aging in comparison to the younger population. 




FIGURE 3 | Dot plots show the gating strategy used to identify plasmablasts (PBs), CD19+, CD27++, and CD38++ in vitro; in four representative PBMCs, one for each group. Histograms show CFSE.

In order to investigate in detail the age-dependent changes of $\mathrm{B}$ cells, we performed a cytofluorimetric and functional study of $B$ cells in the peripheral blood of children and young blood donors and compared them to two groups of older individuals divided according to age ( $65 \geq$ years $<70$ or over 70 years). To avoid health-related bias, we enrolled individuals in the study that did not have an associated co-morbidity or previous diseases of the immune or hematopoietic system.

Besides a general age-related reduction in the percentage of CD19+ B cells, we found specific changes in B cell subpopulations. While naïve, transitional, and $\mathrm{MBCs}$ were reduced in either or both percentages and total numbers, we observed an increase in both the percentage and the absolute number of ATM B cells in older individuals compared to young. These cells have been identified in different contexts that include chronic infection, autoimmunity, and aging (45).

$\mathrm{CD} 27^{\text {dull }}$ MBCs in older people were significantly reduced both in percentage and absolute number, as well as the ratio between $\mathrm{CD} 27^{\text {dull }}$ and $\mathrm{CD} 27^{\text {bright }}$. We have previously demonstrated that $\mathrm{CD} 27^{\text {dull }} \mathrm{MBC}$ s are mostly of the IgM isotype and can be generated without T cells and GC (28). CD27 ${ }^{\text {dull }}$ MBCs are the precursors of $\mathrm{CD} 27^{\text {bright }} \mathrm{MBCs}$. While $\mathrm{CD} 27^{\text {bright }} \mathrm{MBCs}$ produce antibodies that are highly mutated, $\mathrm{CD} 27^{\mathrm{dull}} \mathrm{MBCs}$ are less mutated and may enter the GC reaction in competition with naïve B cells, having the advantage of a more suited transcriptome compared to naïve $\mathrm{B}$ cells (28). Thus the reduction of CD27 $7^{\text {dull }}$ MBCs not only explains the reduction of IgM MBCs observed in the elderly (21) but also explains the diminished ability of elderly people to react to new infections and vaccinations associated with the increased incidence and severity of infections (46).

The dramatic reduction of $\mathrm{CD} 27^{\text {dull }} \mathrm{MBCs}$ in older individuals can explain the reduction of TI immune responses, such as those against Streptococcus pneumoniae (29). Interestingly, the susceptibility to pneumococcal infection is high in neonates whose $\mathrm{CD} 27^{\text {dull }}$ MBCs population is still scarce, reduced in the young and adult populations, where $\mathrm{CD} 27^{\text {dull }} \mathrm{MBCs}$ are abundant, and increased again in the elderly (46).

The significant reduction of $\mathrm{CD} 27^{\text {dull }}$ MBCs also has an impact on sIgA synthesis. We have recently demonstrated that IgM MBCs are necessary for the production of $\operatorname{sg} \mathrm{A}$ at the mucosal surface (47). sIgA is the major player for host defense, providing a first line of effective immunity against pathogens at mucosal sites. The gastrointestinal tract in the elderly is particularly susceptible to infectious diseases, suggesting that poor mucosal immunity is responsible for the higher mortality to infections in aged individuals (48). Interestingly, it has been 




B

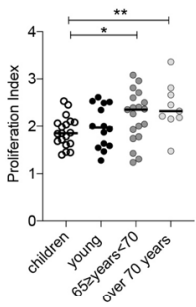



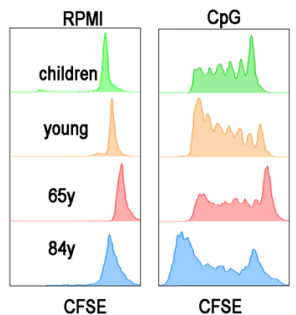

C



FIGURE 4 | (A) Percentage of plasma cells after CpG stimulation (children $n=19$; young $n=14 ; 65 \geq$ years $<70 n=19$; over 70 years $n=9$ ). (B) Proliferation and replication index gated in B cells after CpG stimulation. (C) Plots indicate the concentration of lgM, IgG, and IgA (ng/ml) detected by ELISA in culture supernatants obtained from PBMCs stimulated with CpG. Midlines indicate the median values. Statistical significances were determined using unpaired, two-tailed Mann-Whitney $U$-tests. ${ }^{*} p \leq 0.05 ;{ }^{* *} p<0.01 ;{ }^{* * *} p<0.001$

shown that at older ages there is a failure of induction of the $\operatorname{sg} \mathrm{A}$ antibody resulting in age-related decline in mucosal immunity (49).

B cells fight viruses and bacteria by producing antibodies following their differentiation into circulating plasmablasts. The percentage of plasmablasts increased with age and the ability of the B cells to proliferate and differentiate into plasmablasts seems to not be affected or even improved in older subjects because of the increase of $\mathrm{CD} 27^{\text {bright }} \mathrm{MBC}$ that are closer to the plasma cell stage than CD27 ${ }^{\text {dull }}$ MBCs (28). However, our results from the in vitro studies indicate an impairment of the B cells' function following a TI stimulus and confirm that the most affected antibodies are IgM and IgA.

Thus, the observed plasmablasts number associated with a reduced level of secreted antibodies suggest an impaired capacity to exert their function with age.

Aging is associated with the accumulation of damaged mitochondria, that are less efficient in ATP generation (50). Several studies indicate that autophagy-related (ATG) proteins and other proteins required for autophagy induction, such as Sirtuin 1, are less expressed in aged tissues and that autophagy diminishes with aging (51). Atg $5^{-/-}$murine plasma cells show augmented endoplasmic reticulum stress and cell death, failing to give rise to an efficient antibody response and to form long-lived plasma cells in vivo (52). Atg5 ${ }^{\mathrm{f} / \mathrm{f}} \mathrm{CD} 19$-Cre mice have reduced IgM and IgG responses in both $\mathrm{TI}$ and $\mathrm{T}$-dependent immunization experiments, revealing a key adaptive role of autophagy in shortlived plasma cells and in antibodies responses (52).

Taken together these observations suggest that the defects in autophagy observed in the elderly may explain the functional impairment of immunoglobulin secretion by plasmablasts that we have demonstrated in our experiments.

Understanding how the aging of the immune system works is an important step to protect one of the most sensitive groups of our population, especially in this present pandemic era. In some countries, including Italy, governments have issued special emergency regulations that oblige employers to implement special biohazard prevention measures for older workers (53). Among these measures, the provision of vaccines for older workers who are exposed to biohazards is of the utmost importance. Indeed, a recent report highlights novel aging-related genes and adaptive immune dysregulation with potential contributions to the high severity rate of aged COVID-19 patients (54). Thus, vaccination programs may be implemented for individuals that are between 65 and 70 as well as for workers of older age (over 55 years) in order to improve their protection to be used when the natural immune resources start to fail.

The number of subjects in the over 70 years old group is a limitation of our study. Nevertheless, the results are very homogenous and we have been extremely selective during the recruitment. Healthy elderly people represent $<15 \%$ of the general older population (55) and therefore the subjects who responded to our requirements were rare.

\section{DATA AVAILABILITY STATEMENT}

The raw data supporting the conclusions of this article will be made available by the authors, without undue reservation. 


\section{ETHICS STATEMENT}

The studies involving human participants were reviewed and approved by Bambino Gesù Children Hospital. Written informed consent to participate in this study was provided by the participants' legal guardian/next of kin.

\section{AUTHOR CONTRIBUTIONS}

RC and EP designed the study, analyzed data, and drafted the manuscript. SZ drafted the manuscript. MC, AF, CB, PP, EZ, MS, $\mathrm{GF}$, and ST performed all experiments. RB, MV, and NM collected the samples. MC reviewed the manuscript. All authors contributed to the article and approved the submitted version.

\section{REFERENCES}

1. Agarwal S, Busse PJ. Innate and Adaptive Immunosenescence. Ann Allergy Asthma Immunol (2010) 104(3):183-90. doi: 10.1016/j.anai.2009.11.009

2. Nikolich-Žugich J. The Twilight of Immunity: Emerging Concepts in Aging of the Immune System Review-Article. Nat Immunol (2018) 19(10):1146. doi: 10.1038/s41590-017-0006-X

3. Ma S, Wang C, Mao X, Hao Y. R Cells Dysfunction Associated With Aging and Autoimmune Disease. Front Immunol (2019) 10:318. doi: 10.3389/ fimmu.2019.00318

4. Martin V, Wu YC, Kipling D, Dunn-Walters D. Ageing of the B-Cell Repertoire. Philos Trans R Soc B Biol Sci (2015) 370(1676):20140237. doi: 10.1098/rstb.2014.0237

5. Albright JF, Albright JW. Aging, Immunity, and Infection. D Dries DJ, editor. University of Illinois at Chicago College of Medicine (2003). doi: 10.1385/ 1592594026

6. European Commission - Directorate-General for Economic and Financial Affairs. The 2021 Ageing Report. Underlying Assumptions and Projection Methodologies. In: European Economy Series. Aging Committee of European Commission 2021 (2020). EUROPEAN ECONOMY.

7. Poscia A, Moscato U, La Milia DI, Milovanovic S, Stojanovic J, Borghini A, et al. Workplace Health Promotion for Older Workers: A Systematic Literature Review. BMC Health Serv Res (2016) 16(Suppl 5):329. doi: 10.1186/s12913-016-1518-z

8. Magnavita N. Obstacles and Future Prospects: Considerations on Health Promotion Activities for Older Workers in Europe. Int J Environ Res Public Health (2018) 15(6):1096. doi: 10.3390/ijerph15061096

9. Magnavita N. Productive Aging, Work Engagement and Participation of Older Workers. A Triadic Approach to Health and Safety in the Workplace. Epidemiol Biostat Public Health (2017) 14(207). doi: 10.2427/12436

10. Guan W, Ni Z, Hu Y, Liang W, Ou C, He J, et al. Clinical Characteristics of Coronavirus Disease 2019 in China. N Engl J Med (2019) 382(18):1708-20. doi: 10.1056/NEJMoa2002032

11. Zhou F, Yu T, Du R, Fan G, Liu Y, Liu Z, et al. Clinical Course and Risk Factors for Mortality of Adult Inpatients With COVID-19 in Wuhan, China: A Retrospective Cohort Study. Lancet (2020) 395(10229):1054-62. doi: 10.1016/S0140-6736(20)30566-3

12. Goronzy JJ, Weyand CM. Mechanisms Underlying T Cell Ageing. Nat Rev Immunol (2019) 19:573-83. doi: 10.1038/s41577-019-0180-1

13. Tabibian-Keissar H, Hazanov L, Schiby G, Rosenthal N, Rakovsky A, Michaeli M, et al. Aging Affects B-Cell Antigen Receptor Repertoire Diversity in Primary and Secondary Lymphoid Tissues. Eur J Immunol (2016) 46:48092. doi: 10.1002/eji.201545586

14. Ciabattini A, Nardini C, Santoro F, Garagnani P, Franceschi C, Medaglini D. Vaccination in the Elderly: The Challenge of Immune Changes With Aging. Semin Immunol (2018) 40:83-94. doi: 10.1016/j.smim.2018.10.010

15. Palmer DB. The Effect of Age on Thymic Function. Front Immunol (2013) 4:316. doi: $10.3389 /$ fimmu.2013.00316

\section{FUNDING}

This work was funded by the RF2013-02358960 grant from the Italian Ministry of Health.

\section{SUPPLEMENTARY MATERIAL}

The Supplementary Material for this article can be found online at: https://www.frontiersin.org/articles/10.3389/fimmu.2021.690534/ full\#supplementary-material

Supplementary Figure 1 | Dot plots show the gating strategy used to separate CD19 B cells; CD27 dull and CD27 $7^{\text {bright }}$ MBCs and naïve B cells; transitional (Trans) B cells plasmablasts (PBs); and atypical MBCs (ATM) in four representative PBMCs, one for each group.

16. Dace DS, Apte RS. Effect of Senescence on Macrophage Polarization and Angiogenesis. Rejuvenation Res (2008) 11(1):177-85. doi: 10.1089/ rej.2007.0614

17. Aydar Y, Balogh P, Tew JG, Szakal AK. Follicular Dendritic Cells in Aging, a "Bottle-Neck" in the Humoral Immune Response. Ageing Res Rev (2004) 3 (1):15-29. doi: 10.1016/j.arr.2003.08.002

18. Butcher SK, Wang K, Lascelles D, Lord JM. Neutrophil Ageing and Immunosenescence. In: NeuroImmune Biology. (2004) vol. 4, p. 41-55 doi: 10.1016/S1567-7443(04)80005-X

19. Effros RB, Cai Z, Linton PJ. CD8 T Cells and Aging. Crit Rev Immunol (2003) 23(1-2):45-64. doi: 10.1615/CritRevImmunol.v23.i12.30

20. Koch S, Solana R, Dela Rosa O, Pawelec G. Human Cytomegalovirus Infection and T Cell Immunosenescence: A Mini Review. Mech Ageing Dev (2006) 127 (6):538-43. doi: 10.1016/j.mad.2006.01.011

21. Blanco E, Pérez-Andrés M, Arriba-Méndez S, Contreras-Sanfeliciano T, Criado I, Pelak O, et al. Age-Associated Distribution of Normal B-Cell and Plasma Cell Subsets in Peripheral Blood. J Allergy Clin Immunol (2018) 141 (6):2208-19. doi: 10.1016/j.jaci.2018.02.017

22. WHO. Children: Reducing Mortality. Available at: https://www.who.int/newsroom/fact-sheets/detail/children-reducing-mortality.

23. Pawelec G. Age and Immunity: What Is "Immunosenescence"? Exp Gerontol (2018) 105:4-9. doi: 10.1016/j.exger.2017.10.024

24. Frasca D, Blomberg BB. Aging Affects Human B Cell Responses. J Clin Immunol (2011) 31(3):430-5. doi: 10.1007/s10875-010-9501-7

25. Bondada S, Wu HJ, Robertson DA, Chelvarajan RL. Accessory Cell Defect in Unresponsiveness of Neonates and Aged to Polysaccharide Vaccines. Vaccine (2000) 19(4-5):557-65. doi: 10.1016/S0264-410X(00)00161-4

26. van der Poll T, Opal SM. Pathogenesis, Treatment, and Prevention of Pneumococcal Pneumonia. Lancet (2009) 374(9700):1543-56. doi: 10.1016/ S0140-6736(09)61114-4

27. Dumic I, Nordin T, Jecmenica M, Stojkovic Lalosevic M, Milosavljevic T, Milovanovic T. Gastrointestinal Tract Disorders in Older Age. Can J Gastroenterol Hepatol (2019) 2019:6757524. doi: 10.1155/2019/6757524

28. Grimsholm O, Piano Mortari E, Davydov AN, Shugay M, Obraztsova AS, Bocci C, et al. The Interplay Between CD27dull and CD27bright B Cells Ensures the Flexibility, Stability, and Resilience of Human B Cell Memory. Cell Rep (2020) 30(9):2963-77. doi: 10.1016/j.celrep. 2020.02.022

29. Kruetzmann S, Rosado MM, Weber H, Germing U, Tournilhac O, Peter H-H, et al. Human Immunoglobulin M Memory B Cells Controlling Streptococcus Pneumoniae Infections are Generated in the Spleen. J Exp Med (2003) 197:939-45. doi: 10.1084/jem.20022020

30. Martin V, Wu YC, Kipling D, Dunn-Walters DK. Age-Related Aspects of Human IgM+ B Cell Heterogeneity. Ann NY Acad Sci (2015) 1362(1):153-63. doi: $10.1111 /$ nyas. 12823

31. Cerutti A, Cols M, Puga I. Marginal Zone B Cells: Virtues of Innate-Like Antibody-Producing Lymphocytes. Nat Rev Immunol (2013) 13(2):118-32. doi: $10.1038 /$ nri3383 
32. Lopes-Carvalho T, Kearney JF. Development and Selection of Marginal Zone B Cells. Immunol Rev (2004) 197:192-205. doi: 10.1111/j.01052896.2004.0112.x

33. Roederer M. Interpretation of Cellular Proliferation Data: Avoid the Panglossian. Cytometry A (2011) 79(2):95-101. doi: 10.1002/cyto.a.21010

34. Hao Y, O’Neill P, Naradikian MS, Scholz JL, Cancro MP. A B-Cell Subset Uniquely Responsive to Innate Stimuli Accumulates in Aged Mice. Blood (2011) 118(5):1294-304. doi: 10.1182/blood-2011-01-330530

35. Rubtsov AV, Rubtsova K, Fischer A, Meehan RT, Gillis JZ, Kappler JW, et al. Toll-Like Receptor 7 (TLR7)-driven Accumulation of a Novel CD11c+ B-Cell Population Is Important for the Development of Autoimmunity. Blood (2011) 118:1305-15. doi: 10.1182/blood-2011-01-331462

36. Wang S, Wang J, Kumar V, Karnell JL, Naiman B, Gross PS, et al. IL-21 Drives Expansion and Plasma Cell Differentiation of Autoreactive CD11chiTBet+B Cells in SLE. Nat Commun (2018) 9:1758. doi: 10.1038/s41467-01803750-7

37. Jenks SA, Cashman KS, Zumaquero E, Marigorta UM, Patel AV, Wang X, et al. Distinct Effector B Cells Induced by Unregulated Toll-Like Receptor 7 Contribute to Pathogenic Responses in Systemic Lupus Erythematosus. Immunity (2018) 49:725-739.e6. doi: 10.1016/j.immuni.2018.08.015

38. Rubtsova K, Rubtsov AV, van Dyk LF, Kappler JW, Marrack P. T-Box Transcription Factor T-Bet, a Key Player in a Unique Type of B-Cell Activation Essential for Effective Viral Clearance. Proc Natl Acad Sci (2013) 110:E3216 LP-E3224. doi: 10.1073/pnas.1312348110

39. Knox JJ, Buggert M, Kardava L, Seaton KE, Eller MA, Canaday DH, et al. T-Bet+ B Cells Are Induced by Human Viral Infections and Dominate the HIV Gp140 Response. JCI Insight (2017) 2:e92943. doi: 10.1172/ jci.insight. 92943

40. Oliviero B, Varchetta S, Mele D, Mantovani S, Cerino A, Perotti CG, et al. Expansion of Atypical Memory B Cells Is a Prominent Feature of COVID-19. Cell Mol Immunol (2020) 17(10):1101-3. doi: 10.1038/s41423-020-00542-2

41. Ubillos I, Campo JJ, Requena P, Ome-Kaius M, Hanieh S, Rose H, et al. Chronic Exposure to Malaria Is Associated With Inhibitory and Activation Markers on Atypical Memory B Cells and Marginal Zone-Like B Cells. Front Immunol (2017) 8:966. doi: 10.3389/fimmu.2017.00966

42. Kogut I, Scholz JL, Cancro MP, Cambier JC. B Cell Maintenance and Function in Aging. Semin Immunol (2012) 24(5):342-9. doi: 10.1016/j.smim.2012.04.004

43. Capolunghi F, Cascioli S, Giorda E, Rosado MM, Plebani A, Auriti C, et al. CpG Drives Human Transitional B Cells to Terminal Differentiation and Production of Natural Antibodies. J Immunol (2008) 180:800-8. doi: 10.4049/ jimmunol.180.2.800

44. Xie X, Shrimpton J, Doody GM, Conaghan PG, Ponchel F. B-Cell Capacity for Differentiation Changes With Age. Aging Cell (2021) 20(4):e13341. doi: 10.1111/ acel.13341

45. Knox JJ, Myles A, Cancro MP. T-Bet+ Memory B Cells: Generation, Function, and Fate. Immunol Rev (2019) 288(1):149-60. doi: 10.1111/imr.12736

46. Janssens J, Krause K. Review Pneumonia in the Very Old. Lancet Infect Dis (2004) 4:112-24. doi: 10.1016/S1473-3099(04)00931-4
47. Carsetti R, Di Sabatino A, Rosado MM, Cascioli S, Piano Mortari E, Milito C, et al. Lack of Gut Secretory Immunoglobulin A in Memory B-Cell Dysfunction-Associated Disorders: A Possible Gut-Spleen Axis. Front Immunol (2020) 10:2937. doi: 10.3389/fimmu.2019.02937

48. Schmucker DL, Heyworth MF, Owen RL, Daniels CK. Impact of Aging on Gastrointestinal Mucosal Immunity. Dig Dis Sci (1996) 41(6):1183-93. doi: 10.1007/BF02088236

49. Sato S, Kiyono H, Fujihashi K. Mucosal Immunosenescence in the Gastrointestinal Tract: A Mini-Review. Gerontology (2015) 61(4):336-42. doi: 10.1159/000368897

50. Zhang H, Puleston DJ, Simon AK. Autophagy and Immune Senescence. Trends Mol Med (2016) 22(8):671-86. doi: 10.1016/j.molmed.2016.06.001

51. Rubinsztein DC, Mariño G, Kroemer G. Autophagy and Aging. Cell (2011) 146(5):682-95. doi: 10.1016/j.cell.2011.07.030

52. Pengo N, Scolari M, Oliva L, Milan E, Mainoldi F, Raimondi A, et al. Plasma Cells Require Autophagy for Sustainable Immunoglobulin Production. Nat Immunol (2013) 14(3):298-305. doi: 10.1038/ni.2524

53. Ministry of health. Circolare Del 29/4/2020 Updates and Clarifications With Particular Regard to Fragile Workers (2021). Available at: https://www. lavoro.gov.it/documenti-e-norme/normative/Documents/2020/Circolare-n13-del-04092020-lavoratori-fragili-SARS-CoV-2.pdf (Accessed March 11, 2021).

54. Zheng Y, Liu X, Le W, Xie L, Li H, Wen W, et al. A Human Circulating Immune Cell Landscape in Aging and COVID-19. Protein Cell (2020) 11 (10):740-70. doi: 10.1007/s13238-020-00762-2

55. Uyemura K, Castle SC, Makinodan T. The Frail Elderly: Role of Dendritic Cells in the Susceptibility of Infection. Mech Ageing Dev (2002) 123:955-62. doi: 10.1016/s0047-6374(02)00033-7

Conflict of Interest: The authors declare that the research was conducted in the absence of any commercial or financial relationships that could be construed as a potential conflict of interest.

Publisher's Note: All claims expressed in this article are solely those of the authors and do not necessarily represent those of their affiliated organizations, or those of the publisher, the editors and the reviewers. Any product that may be evaluated in this article, or claim that may be made by its manufacturer, is not guaranteed or endorsed by the publisher.

Copyright (c) 2021 Ciocca, Zaffina, Fernandez Salinas, Bocci, Palomba, Conti, Terreri, Frisullo, Giorda, Scarsella, Brugaletta, Vinci, Magnavita, Carsetti and Piano Mortari. This is an open-access article distributed under the terms of the Creative Commons Attribution License (CC BY). The use, distribution or reproduction in other forums is permitted, provided the original author(s) and the copyright owner(s) are credited and that the original publication in this journal is cited, in accordance with accepted academic practice. No use, distribution or reproduction is permitted which does not comply with these terms. 